been intensive, entailing about five 3.5 litre exchanges for an adult. The factor(s) removed by plasma exchange and the mechanism by which it has a beneficial effect have not been identified. ${ }^{3}$ Possibly it is not the removal but the infusion of a plasma component which is responsible. Further studies of mechanisms, timing, and choice of replacement fluids should enhance our understanding.

Chronic inflammatory demyelinating polyradiculoneuropathy has a slower time course than Guillain-Barré syndrome, which usually reaches its nadir in two or three weeks. ${ }^{23}$ It runs a progressive or chronic relapsing course lasting months or years and, according to many anecdotal reports, may be benefited by steroids. "The beneficial effect of alternate day prednisolone was confirmed in a double blind controlled trial. ${ }^{12}$ Various immunosuppressive drugs have been used to good effect in individual cases, ${ }^{11}$ but controlled trials have not been performed. Plasma exchange has also been reported to be of value, ${ }^{11}$ and a brief report of a double blind controlled trial supports its use. ${ }^{13}$ With increasing evidence for the beneficial effect of immunosuppressive treatment on peripheral nerve inflammatory demyelination the outcome of trials of similar treatment regimens in multiple sclerosis is awaited with interest.

RichaRd A C HUGHES

Consultant Neurologist,

Guy's Hospital,

London SE1 9RT

1 Hughes RAC, Newson-Davis J, Perkin GD, et al. Controlled trial of prednisolone in acute polyneuropathy. Lancet 1978;ii:750-3.

Dyck PJ. Current concepts in neurology: the causes, classification and treatment of peripheral neuropathy. N Engl f Med 1982;307:283-5.

3 Hughes RAC, Winer JB. Guillain-Barré syndrome. In: Matthews WB, Glaser G, eds. Recent advances in climical neurologv. Oxford: Blackwell Scientific, 1984:19-49.

4 (ircenwood RJ, Newson Davis J, Hughes RAC, et al. Controlled trial of plasma exchange in acute inflammatory polyradiculoneuropathy. Lancet 1984;i:877-9.

Mendell JR, Kissel JT, Kennedy MS, et al. Plasma exchange in acute inflammatory polyradiculoneuropathy: a controlled randomised trial. Ann Neurol 1983;14:122.

6 Osterman PO, Fagius J, Lundemo G, et al. Beneficial effects of plasma exchange in acute inflammatory polyradiculoneuropathy. Lancet 1984;ii:1296-8.

Raphael JC, Chastang C. Cooperative randomised trial of plasma exchange in Guillain-Barré svindrome. Preliminary results. Ann Med Interne (Paris) 1984;135:8

8 Guillain-Barré Syndrome Study Group. Plasmapheresis and acute Guillain-Barré syndrome Neurologv 1985;35: 1096-104.

9 Ropper AH, Shahani BT. Diagnosis and management of acute areflexic paralysis with emphasis on Guillain-Barré syndrome. In: Asbury AK, Gilliatt RW, eds. Peripheral nerve disorders-a practical approach. London: Butterworths, 1984:21-45.

10 Shumak KH, Humphrey JG, Chiu JY, Routledge ML, Humphrey HE. Toronto General Hospital controlled trial data on plasma exchange in Guillain-Barré syndrome. Ann Med Interne (Paris) 1984;135:9.

11 Dyck PJ, Arnason BGW. Chronic inflammatory demyelinating polyradiculoneuropathy. In: Dyck PJ, Thomas PK, Lambert EH, Bunge R, eds. Peripheral neuropathy. Philadelphia: W B Saunders, 1984:2101-14

12 Dyck PJ, O'Brien PC, Oviatt KF, et al. Prednisone improves chronic inflammatory demyelinating polyradiculoneuropathy more than no treatment. Ann Neurol 1982;11:136-41.

13 Dyck PJ, Pineda A, Daube J, et al. Plasma exchange in chronic inflammatory demyelinating polyradiculoneuropathy, a controlled double blind trial. Ann Med Interne (Paris) 1984;135:9.

\section{PHLS reform. Professional advisers' views over-ruled}

Earlier this year we criticised the proposal by the Department of Health and Social Security that the 52 regional and area laboratories of the Public Health Laboratory Service should be transferred to local health authorities. ${ }^{1}$ The report produced for the DHSS by its review team gave the impression that its members were unable to assess the disastrous effects such a transfer would have on epidemiological microbiology. Those in touch with the review were anxious to know how the respected professional advisers to the review team had come to agree to that potentially disastrous recommendation. For clearly Professor Ian Phillips and Dr Robert Blowers would have given sound advice.

The truth has now emerged: the review team knew that its professional advisers disagreed with its main recommendation, but it went ahead with circulating the report, refusing the advisers' request to include their comments as an addendum or to distribute them to all recipients of the report. Happily the advisers have felt free to make their views known independently. Their widely circulated comments (see $\mathrm{p}$ 683) confirm that they disagreed with the main recommendation. These comments also show that the advisers are concerned that the team was composed entirely of DHSS administrative staff with its only scientific member not from epidemiology or preventive medicine. "Serious misunderstandings by the team would have been avoided," say the advisers "if its membership had included a medical microbiologist and representatives of the other main user groups of the PHLS such as an epidemiological medical officer of health, a clinical consultant, and a medical general practitioner."

They go on to emphasise the vital part that epidemiological microbiology plays in preventive medicine: its current importance to the health of people in general is apparent from the effective control and limitation of extremely dangerous and unpleasant infections such as the acquired immune deficiency syndrome, Legionnaires' disease, institutional outbreaks of salmonellosis, and hospital acquired infection with methicillin resistant staphylococci. They believe that the proposals would bring to an end training programmes in epidemiological microbiology and that experts in that discipline would soon become extinct.

These and other criticisms from its own advisers must cast grave doubts on the validity of the DHSS inquiry. The evidence now points to the main proposal of the DHSS report being decided regardless of the evidence and arguments. Indeed, the costly review enterprise-all $£ 135000$ of it-seems to have had little purpose other than to give a plausible but bogus respectability to a foolish piece of vandalism.

Because it concerns communicable disease, microbiology is a hospital service which provides information relevant not only to the care of individual patients but to the benefit of the population as a whole. The PHLS in its central role and in its peripheral activities in district hospitals and the community must be able to transcend district and regional boundaries, even as microbes themselves transcend them. Only by gathering good quality information from a proper sample of hospitals can the PHLS function as an effective component of preventive medicine. Without well trained epidemiologically motivated microbiologists within hospitals, where the problems present themselves, the PHLS will lose its most useful source of accurate information and its capacity to set up multicentre studies of microbial diseases. If the link between the centre and the periphery is broken it will take the end of only one generation of epidemiologically motivated microbiologists for all these benefits to fade away.

The PHLS has always understood that its freedom over its day to day operations depended on its giving a good service. There has been no suggestion that it has failed in its duty. There must now be a question about the understanding of those at the DHSS who produced the review team's report in defiance of its professional advisers' advice.

1 Howie J. Threat to the PHLS. Br Med f 1985;290:579-80. 